\title{
Agbiotech goes Canadian
}

Strange but true: The emerging center (or should I say, centre) of agricultural biotechnology $\mathrm{R} \& \mathrm{D}$ is in the unlikely location of Saskatoon in Saskatchewan, in western Canada. Saskatoon's rise to prominence may be attributed in part to the dive in corporate and venture capital enthusiasm for new agbiotech companies in the U. S.

After a heady number of new agbiotech start-ups during the 1978-1982 period, new company formation languished. Of the $\$ 2.6$ billion the venture capital community invested in U. S. companies in 1994 , about $\$ 973$ million went to life science companies. Of that total, agbiotech attracted a paltry $\$ 30$ million or so. Commentators attribute the starvation of new U.S. agbiotech enterprises variously to the attractiveness of alternative investments in medical biotechnology, growing activist militancy, or the erratic financial performances of existing agbiotech firms.

New agbiotech products have also been stricken with the perception that they take decades, not years, to perfect. Moreover, the handling in both Europe and the U.S. of patent controversies in agbiotech has puzzled venture investors. Instead of upholding and supporting agbiotech inventors to the fullest extent, large agribusiness companies, occasionally in alliance with the U.S. Department of Agriculture (Washington, D. C.), have moved to unseat fundamental agbiotech patents.

Recent examples include reexaminations of Agracetus' (Middleton, WI) patent covering genetically engineered cotton and Mycogen's (San Diego, CA) patent on sunflower high in oleic acid. Venture investors in the U.S. liken these actions to "eating our young." In Europe, the biotechnology patent directive, designed to clarify national patent legislation, foundered on issues such as the conflict between plant breeders rights and patent rights, and on the question of the "farmers' privilege" to recycle patent-protected seed.

As the verve for agbiotech has dwindled, Saskatoon has entered the void. Two calculated steps form the basis of the city's strategy. First, Saskatoon formed a development company to advocate agbiotech and to speed the formation of new startups. The nonprofit Ag-West Biotech (Saskatoon) was chartered in 1989 to position the city and the province among the world leaders in agbiotech. From practically nothing, Saskatoon has become one of the top five entrepreneurial centers for agriculture in the world.

During the 1990s, the number of agbiotech companies in Saskatoon tripled. Innovation Place, Saskatoon's new research park, now serves as an incubator or headquarters for more than two dozen agbiotech organizations. Recently, international heavyweights Pioneer Hi-bred (Des Moines, IA) and Groupe Limagrain (Chappes, France) established breeding stations in Saskatoon. The vanguard in plant genetics joins the everpresent Saskatoon research operations of Monsanto (St. Louis, MO), DowElanco (Indianapolis, IN), American Cyanamid (Wayne, $\mathrm{NJ}$ ), AgrEvo(Frankfurt, Germany), and others. Murray McLaughlin, president of Ag-West Biotech, estimates that over 800 scientists in Saskatoon spend more than $\$ 100$ million annually on agbiotech R\&D.

The second leg of Saskatoon's strategy was to become the undeniable leader in canola, the rape variety that provides high-quality edible vegetable oil. It was in western Canada in the early 1960 s that researchers began breeding the crop. The goal was to distinguish it from ordinary rapeseed by eliminating two compounds that caused significant animal and human health problems-erucic acid in the oil and glucosinolates in the meal. The first canola varieties appeared on the Canadian prairie in 1974.

Today, Canada plants over 14 million acres. Canola is also invading the 5 million acres of rapeseed throughout Europe and is gaining a foothold in the U. S., too. Canola innovators, such as Calgene (Davis, CA) and Plant Genetic Systems (Ghent, Belgium), maintain beachhead op- erations near Saskatoon.

Of course, Saskatoon's strategy is only a good as the money that backs it. Sources of capital to fuel Saskatoon's ambitions are both impressive and diverse. The Royal Bank of Canada, for example, has designated Saskatoon as its base for its new $\$ 30$ million agbiotech fund. Leverage is also available in Saskatchewan from Western Economic Development.

Since 1988, this initiative has provided over $\$ 10$ million for projects with a total value of more than $\$ 43$ million. The province also maintains an Agriculture Development Fund that contributes over $\$ 5$ million annually to the region's agbiotech community. Finally, the provincial stock exchanges permit private and public securities placements for those enthused about the growth of local companies in western Canada. In recent years, these capital markets have provided tens of millions of dollars in equity for agstartups. Four new agricultural funds have recently committed over $\$ 200 \mathrm{mil}$ lion to advance agricultural development in western Canada over the next decade.

To this mix of strategy, history, and financial muscle you must then add the academic strength of the area-over 400 scientists at the 11 R\&D stations of Agriculture and Agri-Food Canada, the world-class Plant Biotechnology Institute of the University of Saskatchewan, and Canada's well-known Veterinary Infectious Disease Organization, to name just a few. IIn mid1996, Saskatoon will host the large International Conference for Agricultural Biotechnology. By 2000, Ag-West's Murray McLaughlin expects sales from agbiotech products from Saskatchewan to exceed $\$ 200$ million. The fulfillment of that potential will be a loss to Europe and the U.S. and a gain for western Canada.

/II

George Kidd is president of management consultants, Kidd \& Company, Inc. (Shorewood, WI). Email: georgekidd@eworld.com.

(c) George H. Kidd.
Four new

agricultural

funds have

recently

committed

over $\$ 200$

million to

advance

agricultural

development

in western

Canada over

the next

decade. 